\title{
Story, not Gadget. Digital Media as Art Materials and Curatorial Tools in Early Childhood Art Education
}

\author{
Marta Cabral \\ Columbia University Teachers College, USA
}

\begin{abstract}
An important point of using materials in art is to explore their characteristics and possibilities, connecting them with thoughts and experiences to investigate and make sense of ideas and the world. Through art materials, artists create and narrate their own stories. This article argues that if used to bring forth individual voices in social contexts, digital technologies can be important tools in early childhood education. Augmented Reality (AR) and Quick Response Codes $(Q R)$ are not often used in early childhood education, but have an immense potential as curatorial tools in exhibiting young children's work. As with any other more or less traditional materials, digital media are here used for the possibilities they offer artists to explore and communicate. More than being "fancy gadgets," materials are powerful tools to create and tell stories.

This article focuses on an art exhibition showing works by young children in a professional gallery setting, and explore uses for these digital tools in social contexts. After introducing the context for this annual exhibition as part of an early childhood center's art program for infants, toddlers, and preschoolers, this article explores potential uses of these technologies to enhance visitor experience and increase the presence and impact of the artists' voices. The goal of using this kind of technology is set in the kind of artistic, learning, and emotional experiences its use allows and encourages for children and adult visitors. Connecting ideas and concepts from curatorial, educational, and artistic perspectives, this article offers discussions and conclusions relevant to the fields of art and early childhood education.
\end{abstract}

\section{Introduction}

The use of digital media is often seen as something with its own intrinsic value, which will bring advantages simply by virtue of its own use. It is not unusual that we focus on "the gadget," showcasing it as something worth celebrating per se and to which everything else is subservient. These media, although fairly mainstream today, are often still regarded as novelties in some art educational contexts: "new technologies" or "fancy materials." However, digital media may also be seen as just another "traditional" art material, valued for their properties and the learning and exploring possibilities they allow for. Regarded in this way, as unexceptional tools with their own characteristics, possibilities, and limitations, digital media can be explored as part of artmaking and used in ways that may promote artistic and social engagement. If materials are a crucial part of art education and exploring them a way of learning and thinking in which teaching should be based [1], explorations with digital materials can be seen as part of the curriculum like any other.

Recent studies in 3D design and printing [2], [3] suggest that young children engage with digital materials in similar ways to clay, paint, and other more familiar and traditional art materials. Though adult educators may show concern about "preparing" the children for non-traditional media, children themselves raise no distinction between them. They can engage with 3D design and printing, for example, in similar exploratory ways that they do with sketchbooks and markers, or clay and its tools [3].

With digital media, children tend to focus on the materials' own characteristics and specificities, and the possibilities they offer for them to explore their ideas and tell their stories. This echoes the explorations we see with commonplace artmaking materials. For example, as young artists discover that colors in paint can be mixed together to create new colors, or that glue lets them combine different objects in layers, they begin to realize that each material can be used to create narratives in special ways, just as they discover that Augmented Reality software allows them to make their photos come to life in videos, that QR codes can stand in for photos, or that $3 \mathrm{D}$ printing can be used to create objects designed by combining various shapes on a screen.

In this way, the use of digital materials is not about technological novelty, nor is it dependent on gadgets that might not be common in many schools. On the contrary, exploring digital and less traditional art materials becomes about creating new storytelling possibilities, and expanding the range of media used 
to grapple with ideas - to make sense of the world and our place in it.

\section{An art exhibition: engaging with works by infants, toddlers, and preschoolers and the use of digital materials}

It's a Tuesday morning and my preschoolers are getting ready to go up to the art gallery where their artworks are exhibited. Every year, the gallery that is at the core of the Art \& Art Education Program at Teachers College Columbia University welcomes an exhibition featuring works by the infants, toddlers, and preschoolers I teach at the Rita Gold Early Childhood Center, an on-campus lab-school for young children. As the Center's Artist-in-Residence and Research-Fellow I run the art program and curate this exhibition alongside with my young students. That morning, a few children and I make our way to the gallery to welcome a group of young visitors from another on-campus school.

"Let's play my artist statement now!" Pablo yells out loud as we welcome our visitors for another guided tour. Like the other preschoolers, Pablo performed his artist statement for my camera, talking about himself as an artist. The resulting video is now visible through Augmented Reality to every visitor that scans his photo on a poster exhibited on the gallery wall, right next to his artwork. Each one of Pablo's artworks has its own statement (sometimes on video, sometimes in text or a photo) available through QR codes specific to each work.

Pablo is five years old and he is an artist whose favorite media are glass and paint. He also enjoys cooking. When he grows up, Pablo wants to be an artist and a chef, as he explains in his artist statement. Walking visitors through the gallery, Pablo takes a double role as artist and museum educator: he is an exhibited artist, and as his work is currently being shown in this exhibition, he also acts as a tour guide. In his guided tours, Pablo shows visitors artworks by him and his fellow artists, talks about processes and materials, engages visitors in interpretative dialogues [4], and answers any questions his guests may have. He also teaches them how to use Augmented Reality and Quick Response codes with digital devices to interact with the artworks. Sometimes he holds the devices himself;on other occasions he invites his visitors to so so. Some days he even engages visitors in playful performances based on what they see in the artist statement videos.

Augmented Reality (AR) allows for pictures to be "turned into" videos when read by a smartphone or tablet with the appropriate software, which is free and widely available. The viewer points her phone at an image (the target), and the device shows a video playing over this target in a loop for as long as the device is pointing at it and reading it. In the case I am describing here, this is what it looks like:

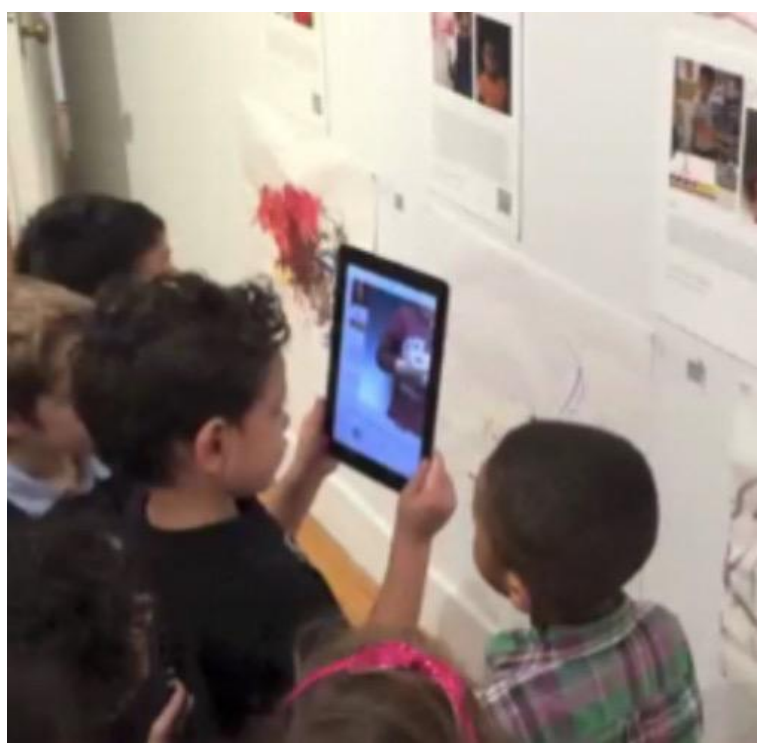

Figure 1. Children interacting with AR

The visitor - in this image it is the young artist in the photo himself - points a smart device (in this case an iPad) at the target: a photo of the artist taken against a gradated black backdrop. The smartphone reads the target and displays a video of the same artist performing his artist statement, recorded against the same backdrop for visual consistency. So the viewer starts by seeing a still image that is then overlapped by a video. This means that if the visitor is looking through the phone he sees a video; if not, the visitor sees a still photo. This still image also works on its own as a stand-alone portrait of the artist, even if visitors choose not to activate AR: even though it gives the AR user a special view of the artist statement through a video, each child's photo also provides the experience of the artist portrait to visitors who rather not engage with the AR technology.

Quick Response (QR) codes are fairly common, but often used more for commercial, informational, and practical purposes (such as to provide marketing information, to incentivize social media sharing of products, or to inform passengers on bus stops about schedules and fares). Art-related purposes are less commonly addressed in mainstream use, but there are examples of artistic uses of QR codes in fashion (http://thorunndesign.com/about/), artquitecture, (qrcodegarden.co.uk or turismodeportugal.pt), etc. Institutions like University of Manitoba have created community art projects involving digital technologies [5], but much of the online literature on QR use relates more specifically to libraries. In school contexts, even though there are many online lists of 'fun' uses of QR codes to assist practical 
learning, these are still relatively unused media in academic or art related contexts.

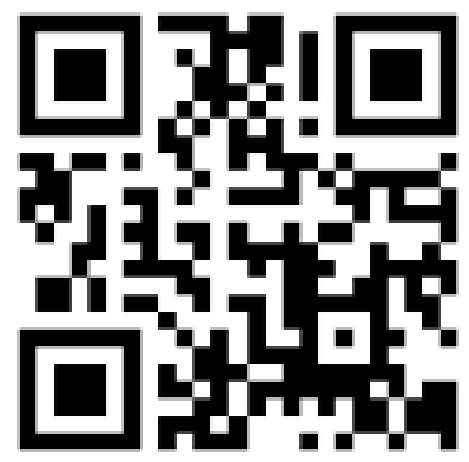

Figure 2. QR code (scannable with a $\mathrm{QR}$ reader)

QR codes like the one above offer an easy way to directly connect audiences with information that might not need to be physically present at all times. This extra information can be stored online and be instantly and directly accessed by smartphones and other devices, by viewers individually or in a group. In the case of the Rita Gold exhibition, this makes it possible to bypass the need for large amounts of text to be physically present next to each artwork, which could distract visitors from the artwork itself. QR codes allow for information to be present but hidden from the naked eye.

This efficient sharing of information is particularly important at an institution like the RGC, offering a child-centered curriculum with a high child-adult ratio. In RGC art sessions, children work individually and free from set guidelines on what their work should be or look like. This means they often have much to say about their explorations.

On the other hand, because each chid benefits from a large amount of individual attention, this input in terms of thoughts, comments, or narratives is extensively documented through written statements, photos, videos, etc. The amount of information available for each artwork is often immense, and while it may significantly add to the viewer's experience, it could also clutter the exhibition if not carefully presented.

The use of digital media as curatorial tools may also be particularly relevant when working with preliterate (and often preverbal) children, as well as foreign language speakers and non-literate audiences and artists of any age. By allowing both artists and viewers to engage with artworks in ways that do not require reading or writing but are the same to everyone, we are valuing forms of communication and curation which do not require mastery of the written language.

Made visible through the use of a personal device at any time, QR codes don't take away from the experience of viewing artworks as they are. Instead, they offer added context and information for viewers who choose to use them. Using any of several apps that are widely available and free to download, any visitor to the exhibition can scan the $\mathrm{QR}$ code next to each artwork and make instantly available information such as photos or videos of the artists at work, PDF documents with artist statements, etc. In the case of this exhibition, each artwork was linked to a document containing more information about the piece: either a photo or video of the artist at work, a video of the artist talking about the piece, or a PDF document with the artist's words or contextual information about the work exhibited.

Some of these videos and photos were candid shots of the children engaging with art materials, others were formal artist statements that children performed specifically for the exhibition. Some PDFs contained informal anecdotes and contextual information about each artist and their practices with materials; others were more intentional and focused, with videos or statements by older children intentionally commenting on their artwork, the techniques they used, and the artistic decisions that accompanied their processes.

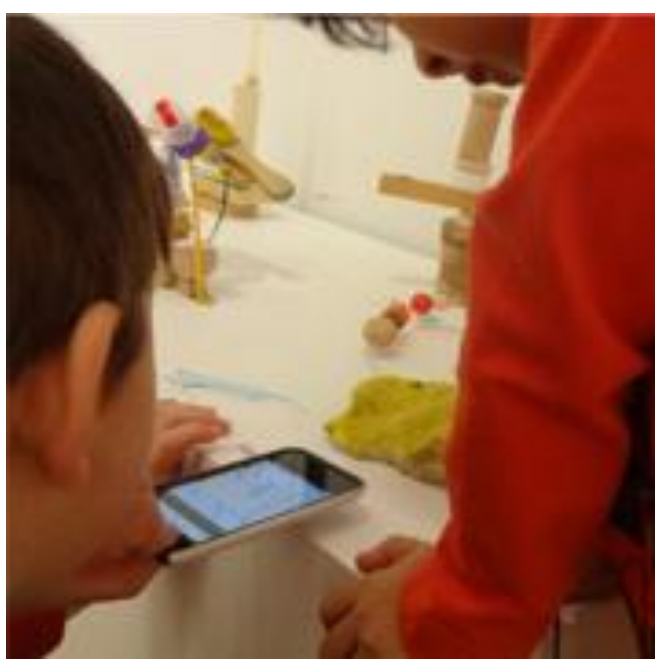

Figure 3. Children interacting with QR codes

Figure 3 shows two preschoolers interacting with QR codes. This image shows them demonstrating to viewers how $\mathrm{QR}$ codes can lead them to more info on each piece, while they guide visitors through their exhibition and make available more information about the artworks on view.

\section{The school, the art program, and their educational context}

The interactions I am here describing take place in the context of a Studio Art Program which I run for infants, toddlers, and preschoolers. This means I work with every child in school over the course of 
each week, sometimes individually, other times in small groups or with the entire classroom as a group, in my art studio at the school, in each classroom, in the art gallery, or in one of the many art studios on campus that the Art \& Art Education program generously makes available to us. We are a small center with one classroom for each age group (infants, toddlers, and preschoolers) and a total of around 40 children. The school has a play-based emergent curriculum: more then a set of guidelines and lesson plans, curriculum is built by children and staff according to what ideas, questions, and needs emerge in their day-to-day lives. The RGC children spend most of their time engaging in free unstructured play, along with more directed weekly activities like music, dance, or sports. Even though there is a broad daily schedule (which includes visits to outdoor spaces, lunch, nap, etc) the core of children's play is self-directed.

The RGC art program is designed in accordance with the school's philosophy, in which the children's individual voices are welcomed and fostered. My jobs is to create the conditions for each child to explore materials at their own pace and according to their own individual inclinations. This doesn't mean I don't suggest materials or establish some guidelines for their use - safety is of course the first priority and respect for peers and materials is key. What it means is that instead of having a fixed curriculum which insists that everyone participate at the same time and in the same way, I provide space, materials, and the physical, intellectual, and emotional scaffolding for children to explore at their own pace. According to their own ideas, interests, and rhythms, each child is supported in their own learning process. As a pedagogue and a fellow artist, I focus on how rich my children's experiences can be, how I can support them in creating those experiences, and what they will learn - not on what they will make. This means that I have learning objectives for my suggested explorations, but I do not have expected outcomes in terms of finished products and physical artifacts produced and what they should look like.

So when the time comes to put together our annual art exhibition, the children's input is equally important. The children and I decide together which artworks to display, and it is not unusual for some children to create a new piece specifically for the exhibition. All children participate in this process as artists, assistant curators, and museum educators. The exhibition is a highlight of the school's calendar - and my own! It becomes an important part of the curriculum and often a benchmark in family life as well. The children are eager to show their work to family, friends, and other visitors, and take active roles in making that happen. The children visit the gallery often throughout the school year, since the early childhood center is an on-campus lab school and we have easy access to it. They know the venue well and recognize it as an art gallery, independently of the artists who are exhibiting at any given moment. Used to visiting different art exhibitions and aware of the gallery as a place for interacting in many ways with the work of different artists, the children take charge of their own interactions with the space and the work, and help their visitors to do the same.

\section{Digital materials as curatorial tools}

\subsection{Digital materials as tools for exhibition design}

To exhibit, Smith argues, is "to bring a selection of $[\ldots]$ works of art, into a shared space (which may be a room, a site, a publication, a web portal, or an app) with the aim of demonstrating, primarily through the experiential accumulation of visual connections, a particular constellation of meanings that cannot be made known by any other means" [6]. As a curator, I question how I can bring together my students' works in such a meaningful manner, significant to the artists themselves, their families, and the broader community?

Because my teaching does not insist on a single way of exploring materials or specific expectations about how an artwork should look like, the pieces produced by children are very diverse in their appearance and in the ways materials are used. They don't necessarily form an obvious body of work with a common theme. Even though children are often inspired by each other and often work side-by-side exploring materials in ways that build on each other's experiments, each child is free to work in their own ways and create and explore as they see fit. Furthermore, the children actively participate as cocurators of this exhibition by deciding which artworks from their body of work they want to exhibit. This means that the pieces they choose are diverse in nature, materials, and technique: this may present a curatorial challenge, if the goal is to have an art exhibition with a coherent identity of its own. How can curatorial decisions preserve and cherish individuality while fostering a sound group identity amongst the works exhibited? A challenge of the exhibition is the need to provide contextual information [7] relative to each piece, but without distracting the visitor's attention from the artwork itself and keeping the exhibition focused on the pieces shown, and not on labels, texts, or footnotes.

This is where digital technologies can be important as curatorial tools: QR codes and AR may provide important solutions for these issues, if used strategically and in a way that adds to the exhibition and the artwork instead of taking away from it. However, the discreteness of QR codes also allows visitors to focus solely on the artworks, if they 
should so wish - the experience might to be as rich, but it is definitely integral and complete in itself.

This dual option for the viewer to engage with the digital technologies or not, and in either case have a cohesive experience of the exhibition, is also an important consideration in the way AR is used in this exhibition. If they so choose, guests may visit the exhibition without the assistance of an electronic device and see photos of each artist next to their artist statements, having a complete experience of the show. However, those photos can be complemented by videos of each artist, potentially enhancing the visitor's engagement with the exhibit, the artists, and the artworks.

These curatorial strategies also offer visitors the option to interact with the digital component in small groups, and share devices as they make their way through the exhibition. This may allow for an extra level of social interaction and can be particularly meaningful for both children and adults. The community aspect of visiting an art exhibition together with peers may offer the obvious opportunity to engage with others through a common experience, potentially sharing thoughts and ideas. As children or adults walk around together in pairs or small groups, they may focus on different aspects and help others notice different things in specific artworks, share ideas about processes and materials, etc.

\subsection{Digital materials as tools for artists and community engagement}

This engagement of artists, visitors, and community is at the core of the curatorial concerns I try to address in this exhibition. If the exhibition is a "conversational setting," [8] it is important to consider who will participate in this "ongoing conversation," [8] and how will it be supported. If "the whole curatorial thing has to do not only with exhibitions, it has a lot to do with bringing people together" [8], the curator "has to bridge gaps and build bridges between artists, publics, institutions, and other types of communities [...in order to build] temporary communities, by connecting different people and practices, and causing the conditions for triggering sparks between them" [8].

The first participants in this engagement are the artists themselves, the children. The exhibition is a big occasion for them, and it is important that their voices are heard as much as possible, and that they are present, engaged, and actively participating throughout the entire process. Having not only their artworks but their words, performances, and statements exhibited and available to visitors is one way of making their engagement as complete as possible.

This naturally happens when the children physically visit the gallery, particularly if they are familiar with the technology, in which case they may take charge of its use by deciding when they want it activated - both when they visit the gallery with me, and maybe even more so when they show visitors around in guided tours. These visitors may be children or adults, both people who the children know and are familiar with or occasional visitors with no personal connections to the artists and their work.

In this circumstance, these children teach adults and other children how to use the AR and QR materials, and in doing so tend to interact with these digital tools in addition to the physical works, supplementing the possibilities of engagement, and not supplanting them. Another important aspect of this interaction is the physical one: as they maneuver iPhones and iPads to show their AR video statements, children learn to negotiate the physical space with visitors around them in very real and current situations. In order to effectively show the videos on the device they are holding, children are forced to find ways to adapt their body motions and positions figuring out where and how they need to stand so that they show the video but do not block the view, how to keep their arms straight out holding the device, or up or down, or bent. These are important decisions that are learned by experimenting and observing [8], making an effort to welcome visitors and share artworks and ideas. The use of shared devices might enhance this experience further, through the practical challenges which face children as they negotiate, for example, how to physically hold the devices in order to be seen by all interested parties, or how to take turns in leading the group. Negotiating their bodies in space and in relationship to others is something young children are in the process of grasping and this use of technology may offer opportunities for them to develop those understandings based on real-life situations that are complex enough to offer challenges (devices need to be held up in ways that make them visible to others) but based on immediate feedback and with simple enough solutions: children will often complain if they can't see and offer suggestions as to how to solve the problem, trying them out right away. When only a single device is available to be held, one child at a time takes the lead in sharing a single artwork or artist statement with others. This turn-taking is negotiated between the tour group. In gallery visits without devices more outgoing or vocal children may tend to take the role of leaders; the use of a hand-held device might counteract this tendency by offering ways for other children to step up as leader - ways that do not depend on a child's willingness to be outspoken or their ability to express themselves verbally.

Guided tours are also opportunities not only to show these digital materials, but also to explain the need for their use. The first QR code audio-tours 
were designed to address a specific need relating to the fact that children can't always be present to physically welcome visitors to the exhibition [9]. "Preschoolers are busy and we don't have much time!" said one young artist, pointing out that between naps and lunchtime and trips to the park, kids can't always be physically present in the gallery to lead guided tours. In these busy times, children can know that their voices and performances are still there even when they themselves are not, and visitors have the opportunity to develop a more complete understanding of each artist's ideas as well.

This dialogue between artists and visitors mediated by technology often continues in the exhibition's guest book, where visitors leave comments that are later on read and discussed by the artists. Children often like to show their friends' work and leave comments about it, and RGC alumni and other older children often write comments "mentoring" younger artists, and offer guidance both in person and in the visitors book after engaging with individual videos and artist statements. Adult visitors, also, often leave notes in our exhibition guest book commenting on specific aspects of artworks or artist statements and asking questions for further discussion.

\section{Conclusion}

Used in ways that support thoughtful curatorial decisions and meaningful artistic and social engagement, digital materials like QR codes and Augmented Reality can be useful tools to engage artists and visitors in art exhibitions. If the use of large amounts of written text next to each artwork providing context may distract visitors from engaging with the work itself, its absence (or shielded presence) may have a more productive result: by allowing visitors to focus on the pieces but still providing contextual information when needed, the use of digital tools may allow for the exhibition to be both comprehensive and easy to navigate. Focusing on the artworks exhibited but providing enough extra information and allowing visitors to proceed at their own pace and will, visitors may design their experience of the gallery according to their own personal preferences.

Besides curatorial devices, digital materials can also be educational tools, providing platforms for young artists to engage with their audiences in meaningful ways. When materials are used to express ideas, young artists may take advantage of the specific characteristics of each material, using them for the possibilities they offer for their personal and individual explorations. With and through materials, children may explore the world and their ideas about it, and these explorations may then be shown to others in meaningful interactions. Like they often do when bringing visitors to see their work.
In the gallery, as they guide visitors through the exhibition, the preschoolers often engage in physical responses to artist statements [10]. For example as they play an artist statement in which one of the boys claims and exemplifies his flying skills, others join in "flying" around the gallery, carefully moving through the space swinging their arms open but being careful not to knock anything down. Following the lead of the tour-guide and of the artist in his statement, visitors imagine different "artist-powers" that they have.

Instead of keeping each child in their own world, sitting down motionless glued to a flat screen (a concern commonly shared by parents and educators), this instance of Augmented Reality use generates a spontaneous burst of joyful play, filled with movement and storytelling. Through this material, artist and tour-guide got their guests to engage in artistic reflections about his work and pretend flying through the gallery. Helping them share their stories was, after all, the gadget's job.

\section{References}

[1] Hafeli, M. C. Exploring studio materials: teaching creative art making to children. Oxford: Oxford University Press, 2014.

[2] Cabral, M. and Justice, S., "Thinking in the making: 3D designing and printing with young children and the creation of thresholds for learning", Proceedings for Edulearn'13 - International Conference on Education and New Learning Technologies, Barcelona, Spain, 2013.

[3] Cabral, M. and Justice, S., "Material learning: digital 3D with children", Proceedings of the meeting of FabLearn 2013. III Digital Fabrication in Education Conference, Stanford, CA, USA, October 27 - 28, 2013.

[4] Hubard, O. "Three modes of dialogue about works of art." Art Education(May), 2010, pp. 40-45.

[5] Valmestad, L.. (2011). Q(a)R(t) Code Public Art Project: A Convergence of Media and Mobile Technology. Art Documentation: Journal of the Art Libraries Society of North America, 30(2), 70-73. Retrieved from http://www.jstor.org/stable/41244068)

[6] Smith, T. Thinking contemporary curating. New York, NY: Independent Curators International, 2012.

[7] Hubard, O. "Productive information. Contextual knowledge in art Museum Education", Art Education(July), 2007, pp. 17-23.

[8] Obrist, H.-U., \& Lamm, A. E., Everything you always wanted to know about curating but were afraid to ask, Berlin: Sternberg Press, 2011.

[9] Cabral, M. Broken things can be beautiful things: early childhood explorations in play and art. New York: Vast Playground, 2014. 
International Journal for Infonomics (IJI), Volume 8, Issue 4, December 2015

[10] Cabral, M. Art makes us happy. Young children explore materials and ideas. New York: PaperStar, 2016. 